\title{
Bariatric surgery for obese live kidney donors: an analysis of risks and benefits
}

\author{
Joseph Brooks $^{1 *}$, Graham Mitro ${ }^{1}$, Anthony DeLeonibus ${ }^{1}$, William McGreevey ${ }^{2}$, Ayla Cash $^{1}$, Samay Jain $^{3}$ and Jorge Ortiz $^{4}$ \\ ${ }^{1}$ College of Medicine and Life Sciences, University of Toledo, Toledo, OH, USA \\ ${ }^{2}$ Department of International Health, School of Nursing and Health Studies, Georgetown University, Washington, USA \\ ${ }^{3}$ Department of Urology, College of Medicine and Life Sciences, University of Toledo, Toledo, OH, USA \\ ${ }^{4}$ Department of Surgery, College of Medicine and Life Sciences, University of Toledo, Toledo, OH, USA
}

\begin{abstract}
Background: Obesity can be a barrier to live donor selection and there are reports of obese live kidney donors (OLKDs) undergoing bariatric surgery prior to donation. While this practice has potential promise, the risks associated with it are unclear. Thus, our aim was to evaluate the advantages and disadvantages of this practice.

Design: Risks and benefits were ascertained from the literature. Analysis of costs and benefits was performed to provide objective data for each scenario.

Results: Live kidney donation is associated with superior outcomes compared to deceased donation. However, live donors are at risk of complications that could be exacerbated by obesity. Higher donor body mass index (BMI) has been associated with inferior recipient outcomes. Bariatric surgery (BS) results in decreased mortality and can induce sustained weight loss. Our cost-benefit analysis revealed a benefit-to-cost ratio of 3.64 for BS prior to live donation by OLKDs. We found ratios of 3.19 and 0.97 for live donation with an obese donor and a deceased donor, respectively.
\end{abstract}

Conclusions: Our results suggest that BS for an OLKD has the potential to increase the number of live donors and improve outcomes. However, more data is required; thus we recommend a registry of patients who have undergone both procedures.

Abbreviations: BS: Bariatric surgery; BMI: Body mass index; DGF: Delayed graft function; ESRD: End-stage renal disease; eGFR: estimated glomerular filtration rate; OLKD: Obese live kidney donor

\section{Introduction}

The rate of living kidney donation has decreased by $13 \%$ over the last decade $[1,2]$. Many potential live donors are often deemed unsuitable. Clinical guidelines indicate that individuals with a body-mass index (BMI) $>35 \mathrm{~kg} / \mathrm{m}^{2}$ should be ineligible or strongly discouraged [3]. Mandelbrot et al. reported that of the transplant centers surveyed, 52\% have a BMI cutoff of $35 \mathrm{~kg} / \mathrm{m}^{2}$ [4]. Others have suggested that $22 \%$ of potential live donors were ineligible due to high BMI [5]. Currently, more than one-third of adults in the United States are obese [6]. Morbid obesity is not only a barrier to live donation, but is also related to a number of medical conditions $[6,7]$.

Bariatric surgery (BS) is a proven and cost-effective treatment for morbid obesity. Reports have indicated that it is an effective method for inducing sustained weight loss, resulting in type-2 diabetes mellitus remission or avoidance, improving glycemic control, and lowering blood pressure [8-10]. It has also been shown to decrease the risk of end-stage renal disease (ESRD) by more than half [11].

Morbid obesity can be a barrier toward increasing live donation. Yet, an effective treatment for morbid obesity exists in BS. There have been reports of obese live kidney donors (OLKDs) undergoing BS prior to live donation. However, little research has been performed on this practice, and while it is potentially promising, it is unclear whether or not the benefits outweigh the risks. National databases such as the United Network for Organ Sharing and the National Surgical Quality Improvement Program do not capture patients who have undergone BS with subsequent live donation. Given that the frequency of this scenario will likely rise with the increasing rate of obesity and a greater need for live donors, we sought to clarify the risk factors associated with it in order to maximize live donor safety and better inform the transplant community. Furthermore, we aimed to determine the costs and benefits such a strategy would have compared to donation from an obese live donor, and a deceased donor.

\section{Methods}

In addition to a review of literature regarding the advantages and disadvantages associated with each scenario, a cost-benefit analysis was performed to provide objective data on the benefits and costs associated with each scenario. Considerations for costs and benefits along with their sources are listed in Table 1 . The nature of the costbenefit analysis is such that every single scenario cannot be accounted for. Thus it is meant as an approximate representation that focuses on the average patient in each category. When presented with a range of

Correspondence to: Joseph Brooks, College of Medicine and Life Sciences, University of Toledo, 5227 Carlingfort Dr., Toledo, OH 43623, USA, Tel: (513) 600-3049; E-mail: Joseph.brooks@rockets.utoledo.edu

Key words: live donors, economics, selection criteria, bariatric surgery

Received: June 26, 2017; Accepted: July 25, 2017; Published: July 27, 2017 
Table 1. Assumptions of the initial cost-benefit analysis.

\begin{tabular}{|c|c|c|}
\hline \multicolumn{2}{|l|}{ Assumption } & \multirow{2}{*}{\begin{tabular}{|l} 
Reference \\
12
\end{tabular}} \\
\hline Cost kidney transplant & $\$ 145,000$ & \\
\hline Cost graft failure & $\$ 88,000$ & 12 \\
\hline $\begin{array}{l}\text { Cost of care for functioning } \\
\text { graft/year }\end{array}$ & $\$ 32,000$ & 12 \\
\hline Cost of dialysis/year & $\$ 121,000$ & 12 \\
\hline Cost of bariatric surgery (BS) & $\$ 30,000$ & 13 \\
\hline $\begin{array}{l}\text { Cost of obesity/yr compared } \\
\text { to non-obese }\end{array}$ & $\$ 7,000$ & 13 \\
\hline Normal life expectancy & 78 & 46 \\
\hline $\begin{array}{l}\text { Years of life left after non- } \\
\text { obese live donor transplant }\end{array}$ & 18 & Extrapolated from 2 \\
\hline $\begin{array}{l}\text { Years of life left after } \\
\text { deceased transplant }\end{array}$ & 13 & Extrapolated from 2 \\
\hline $\begin{array}{l}\text { Years of life left after obese } \\
\text { live donor transplant }\end{array}$ & 15 & Extrapolated from 30 \\
\hline $\begin{array}{l}\text { Years of life left for obese } \\
\text { individual }\end{array}$ & 26 & $\begin{array}{l}\text { Years left }=\text { life expectancy - years } \\
\text { lost - age at donation }\end{array}$ \\
\hline $\begin{array}{l}\text { Years of life lost for obese } \\
\text { individual }\end{array}$ & 7 & 16 \\
\hline Years of life gained after BS & 7 & 16 \\
\hline $\begin{array}{l}\text { Years of life left for BS } \\
\text { recipient }\end{array}$ & 33 & $\begin{array}{l}\text { Years left }=\text { life expectancy - years } \\
\text { lost - age at donation }\end{array}$ \\
\hline $\begin{array}{l}\text { Value of a year of life for } \\
\text { healthy individual }\end{array}$ & $\$ 132,000(2.5 * \mathrm{GDP})$ & 15 \\
\hline Disability weight for obese & 0.83 & 47 \\
\hline Disability weight for normal & 0.9 & 47 \\
\hline Disability weight after Ktx & 0.75 & 12 \\
\hline Diability weight on dialysis & 0.52 & 12 \\
\hline $\begin{array}{l}\text { Value of a year: Obese (Year } \\
\text { value*disabiltiy weight) }\end{array}$ & $\$ 109,560$ & 15,47 \\
\hline $\begin{array}{l}\text { Value of a year: Normal (Year } \\
\text { value*disabiltiy weight) }\end{array}$ & $\$ 118,800$ & 15,47 \\
\hline $\begin{array}{l}\text { Value of a year: After Ktx } \\
\text { (Year value*disability weight) }\end{array}$ & $\$ 99,000$ & 15,47 \\
\hline $\begin{array}{l}\text { Value of a year: On dialysis } \\
\text { (Year value*disabiltiy weight) }\end{array}$ & $\$ 68,640$ & 15,47 \\
\hline Assumed age of donor & 45 years & \\
\hline
\end{tabular}

values for costs or benefits we chose conservatively (that is, values that would decrease benefits) and also performed sensitivity analyses to present ranges of potential benefits and costs.

Regarding the cost of kidney transplantation, graft failure, and care for a functioning graft, we utilized the work of Held et al. from their cost-benefit analysis of government compensation of kidney donors [12]. The cost of dialysis per year and the disability weights for life after kidney transplantation and life on dialysis were also gathered from Held et al. We performed sensitivity analyses for the cost of dialysis using $\$ 90,000 /$ year, $\$ 100,000 /$ year and $\$ 121,000 /$ year. We also performed sensitivity analyses for time on dialysis while awaiting a deceased donor kidney. We chose 2 years, 5 years, and 7 years since 5 years was the average quoted by Held et al.

The average price of BS and the cost of obesity per year were cited from Maciejewski and Arterburn. They reported the estimated cost of $\mathrm{BS}$ to be between $\$ 15,000$ and $\$ 30,000$. Given this wide range, we felt it prudent to choose the highest cost cited for use in our analysis, thus making our final benefits more conservative measures. Regarding the cost of BS itself, it is also important to note that health insurance often covers these costs for the patient. Despite this, it still represents an economic cost that must be included in the analysis. There are many reports referencing the increased healthcare costs associated with obesity per year. Maciejewski and Arterburn reported these costs to range from $\$ 3,000-\$ 10,000$ [13-15]. Cawley et al. suggested the average additional cost of healthcare for an obese individual compared to one of normal BMI is $\$ 3,500$ and that it rises exponentially for class II and III obese individuals [16]. We chose a cost of $\$ 7,000 /$ year as an intermediate estimate [13]. For our initial analysis we used averages of 18 and 13 for years of life left after living and deceased donor transplant, respectively. We made the assumption that donation from an obese live donor would result in worse graft survival compared to a non-obese live donor and better graft survival compared to a deceased donor. Thus, for our initial analysis we used 15 years as the number of years of life left after transplantation with a graft from an OLKD. Since this assumption is loosely based on published reports we also performed sensitivity analyses in which all recipients had the same number of years of life left after transplantation (10 years, 13 years, 15 years, 18 years, and 20 years).

In order to calculate the value of a year of life we utilized the work of David Cutler which suggests that the value of a year of life in a particular country can be calculated as (2.5 x GDP/capita) [14]. For the United States this calculation yields a value per person per year of life of $\$ 132,000$. We performed sensitivity analyses for this value as well $(\$ 100,000$ and $\$ 200,000)$. The value of each year was weighted by the disability weights for each scenario. All benefits were discounted yearly at $3 \%$.

Regarding the benefits of BS, we employed the findings of Peeters et al who suggested that an obese individual who undergoes BS gains 7 years of life expectancy compared to an obese individual who attempts traditional weight loss measures [16]. Given that outcomes after BS can be variable, we performed sensitivity analyses on the number of years of life gained from BS ( 1 year, 3 years, 5 years, 7 years, and 10 years).

The considerations and results of our initial analysis can be found in Table 2. For the BS scenario it was considered that the recipient would spend one year on dialysis. During that same year, the potential OLKD would undergo BS for weight loss. In year 2, kidney transplantation would occur. We also analyzed a scenario in which live donation would occur after 6 months, however, there was not a substantial difference in the results. In each subsequent year, the recipient would incur the costs associated with care of a functioning graft and receive the benefits, of a year of life after kidney transplantation. The last year of graft survival would incur the cost of graft failure and dialysis. Benefits for that year would be weighted at the dialysis weight. The potential OLKD would incur the cost of obesity and BS for the first year. In subsequent years, it was originally considered that the donor who underwent BS would incur no costs relative to the obese donor. However, we also analyzed scenarios in which the donor would incur costs of $\$ 3,000 /$ year, $\$ 4,355 /$

Table 2. Results of the initial cost-benefit analysis

\begin{tabular}{|c|c|c|c|}
\hline & $\begin{array}{l}\text { Donation after } \\
\text { BS }\end{array}$ & Obese donor & Deceased donor \\
\hline Year of transplantation & Year 2 & Year 1 & Year 5 \\
\hline Cost of transplantation (\$) & 177000 & 177000 & 177000 \\
\hline $\begin{array}{l}\text { Years with functioning } \\
\text { graft }\end{array}$ & 18 & 15 & 13 \\
\hline Year of graft failure & Year 20 & Year 16 & Year 18 \\
\hline Cost of graft failure (\$) & 209000 & 209000 & 209000 \\
\hline Cost of BS (\$) & 30000 & 0 & 0 \\
\hline Cost of obesity/year (\$) & 0 & 7000 & 0 \\
\hline Total costs (\$) & 1088000 & 1016000 & 1254000 \\
\hline $\begin{array}{l}\text { Discount rate for benefits/ } \\
\text { year (\$) }\end{array}$ & $3 \%$ & $3 \%$ & $3 \%$ \\
\hline Total benefits (\$) & 3957760 & 3245793 & 1221479 \\
\hline Benefit to Cost Ratios & 3.64 & 3.19 & 0.97 \\
\hline
\end{tabular}


year, and $\$ 4,700 /$ year. These estimates were derived from studies that reported post-BS costs from $\$ 970 /$ year to $\$ 4,355 /$ year $[17,18]$. The benefits for the donor who underwent BS were weighted at the normal disability weight of 0.9 since the individual would be no longer obese. The donor who underwent BS was considered to have a life expectancy longer than that of an obese donor. Analyses were performed for 1-, 3-, 5-, 7-, and 10-years of life gained from BS.

For the obese donor scenario, the recipient was considered to have received a kidney transplant in the first year, thus incurring the cost of transplantation and care for a functioning graft. Each subsequent year the recipient would incur the costs associated with care of a functioning graft and receive the benefits of a year of life after kidney transplantation. The last year would incur the cost of graft failure and dialysis. Benefits for that year would be weighted at the dialysis weight. The OLKD would incur the costs associated with obesity relative to a non-obese individual each year. This was estimated to be $\$ 7,000$. The benefits per year of the obese donor were weighted at the obese disability weight of 0.83 . The obese donor would be expected to have a life expectancy that was shorter than the BS donor.

Finally, for the deceased donor scenario, the recipient was assumed to be on the waitlist and dialysis for 2-, 5-, or 7-years. During each year the recipient would incur the cost of dialysis and accrue benefits weighted for a year on dialysis. On the year of transplantation, the recipient would incur the cost of kidney transplantation along with that for care of a functioning graft. Each subsequent year, the recipient would incur the fee of care for a functioning graft, and accrue benefits for a year of life after kidney transplantation. The final year would incur the cost of graft failure and dialysis. Benefits for the same year would be weighted at the dialysis weight. The deceased donor was assumed to accrue neither benefits nor costs.

Benefit-to-cost ratios were calculated for each scenario. Benefit-tocost ratios are listed in Table 2 . Results of the entire cost benefit analysis are included in Table 3.

\section{Results}

\section{Transplantation after donor bariatric surgery}

It has been well-documented that recipients of living donor transplants experience superior graft survival rates, lower rates of delayed graft function (DGF), and improved quality of life [2,19]. Regarding the donor, Sjostrom et al. found that BS was associated with an overall reduction of mortality compared to conventional weightloss methods [20]. BS results in sustained weight loss and improves hyperinsulinemia, hyperglycemia, dyslipidemia, and hypertension even after 6 months [8-10,21]. Douglas et al. suggested that BS is associated with protective hazard ratios for type- 2 diabetes mellitus, hypertension, angina, and myocardial infarction [22]. Furthermore, a 40,000 patient observational study suggested that BS was associated with a $46 \%$ reduction in heart failure compared to lifestyle interventions [23]. BS is also associated with improvement in estimated glomerular filtration rate (eGFR) and decreased risk of ESRD [11]. Chang et al. also indicated that weight loss in individuals who have undergone bariatric

Table 3. Benefit-to-Cost Ratios After Sensitivity Analysis for the Value of a Year of Life.

\begin{tabular}{|c|c|c|c|}
\hline & \multicolumn{3}{|c|}{ Value of a year of life (before weighting) } \\
\hline Scenario & $\mathbf{\$ 1 0 0 , 0 0 0}$ & $\mathbf{\$ 1 3 2 , 0 0 0}$ & $\mathbf{\$ 2 0 0 , 0 0 0}$ \\
\hline Bariatric surgery & 2.73 & 3.64 & 5.45 \\
\hline Obese, live donor & 2.42 & 3.19 & 4.84 \\
\hline Deceased donor & 0.73 & 0.97 & 1.46 \\
\hline
\end{tabular}

surgery is up to 30-times greater than those who have not had BS [11]. When combined with intensive medical therapy, BS has been shown to be more effective in achieving glycemic control compared to medical therapy alone [24]

There are patients who do not garner these benefits from BS. For example, one report found that $15 \%$ of individuals who undergo BS fail to lose weight. Failure to lose weight was associated with older patient age and increased starting BMI [25]. On top of that, there would be some number of individuals who are unable to donate following BS due to sustained renal insufficiency.

There are risks associated with BS and live donation. The mortality rate following laparoscopic sleeve gastrectomy was $0.11 \%$ after 30 days and $0.21 \%$ after 1-year [26]. This rate indicates that laparoscopic sleeve gastrectomy is safer than gastric bypass (30-day mortality: 0.14\%; 1-year mortality: $0.34 \%$ ) [26]. OPTN data indicates that there were only five donation-related deaths within a year of donation in live donors in 2012 [2]. A recent meta-analysis reported that the mortality rate after live donor nephrectomy was $0.01 \%$ [27]. However, it remains unclear what percentage of previously obese individuals who undergo BS followed by live-donor nephrectomy will subsequently develop renal failure.

Regarding costs, the price of BS can range from $\$ 15,000$ for laparoscopic adjustable gastric banding (LAGB) to $\$ 30,000$ for Rouxen-Y gastric bypass (RYGB) [13]. In a review of hospital charges for bariatric procedures, Livingston reported a median fee of $\$ 22,000$ $[28,29]$. Laparoscopic gastric sleeve is now the most commonly utilized bariatric procedure [30]. Hyperoxaluria is less of a problem in this procedure. However, a potential down side of other bariatric procedures is the risk of the development of kidney stones.

\section{Transplantation with an obese, live donor kidney}

Many guidelines discourage donation by living donors with a BMI $>35 \mathrm{~kg} / \mathrm{m}^{2}$ [30-33]. This is because of risks to both the recipient and the donor. Elevated donor BMI is associated with an increased risk of allcause graft loss [34]. Additionally, recipients of transplants from obese donors are more likely to experience DGF [35].

Locke et al. recently demonstrated the risk of chronic kidney disease is higher among potential live donors who are obese [36]. Additionally, recipients of allografts from donors who subsequently developed ESRD are at increased risk of graft loss and mortality [37]. Obese individuals also have reduced life expectancy relative to nonobese individuals [16]. Obesity is also associated with hypertension, diabetes, cardiovascular disease, cancer, and chronic kidney disease [6,7]. Furthermore, compared to patients with a normal BMI, it has been demonstrated that obese individuals have over a $500 \%$ increased risk of ESRD [38]. Moreover, living donors are at an increased risk of developing hypertension and experiencing reduced post-donation renal function both of which could be exacerbated by obesity [39-41].

For obese donors, surgery is more difficult to perform and obese patients are expected to have more complications. Laparoscopic surgery is preferred since it is associated with fewer complications and quickened post-surgical ambulation. However, laparoscopic nephrectomy in obese $\left(\mathrm{BMI}>35 \mathrm{~kg} / \mathrm{m}^{2}\right)$ donors takes an average of 40 minutes longer compared to normal weight donors, and is more likely to be converted to an open nephrectomy procedure [42,43]. Obese donors also experience higher intraoperative blood loss [44]. OLKDs are also at significantly greater risk of experiencing Clavien grade II, III, IV, or higher complications compared to donors of normal BMI $[45,46]$ 


\section{Transplantation with a deceased donor kidney}

In 2014 , over 8,000 people died or became too ill to receive a transplant while on the waitlist [1]. Waitlisted patients on dialysis have a mortality rate that is twice as high as those who are transplanted [42]. Expected 5-year survival for a 55-year old person on dialysis is approximately 10 years less than that of an individual of the same age who receives a transplant [47]. Dialysis is associated with a number of complications including anemia, depression, access site infections, etc. Quality of life is also reduced while on dialysis [12]. Dialysis is also associated with a considerable cost. In 2013, Medicare costs for ESRD amounted to $\$ 30.1$ billion [48]. Estimated per person cost of dialysis per year is $\$ 83,000-\$ 121,000[12,48]$.

For those who receive a kidney, death-censored graft failure within 90 days of transplantation and DGF were higher in individuals who received deceased donor transplants compared to living donor transplant recipients [2]. Incidence of acute rejection was higher in recipients of deceased donor transplants relative to living donor recipients [2]. Deceased donor allografts also have a long-term survival rate that is 5-12 years shorter than a living donor allograft [2]

\section{Cost-benefit analysis}

Assumptions for costs and benefits are outlined in the Methods section and listed in Table 1. Results of the initial cost-benefit analysis are listed in Table 2. Benefit-to-cost ratios are listed in Table 2. Sensitivity analysis for the value of a year of life demonstrated a range of benefit-to-cost ratios for each scenario (Table 3). The values for a year of life analyzed were: $\$ 100,000, \$ 132,000$, and $\$ 200,000$. Sensitivity analysis for time on dialysis (two, five, and seven years) for recipients of deceased donor kidneys yielded a range of benefit-to-cost ratios for the deceased donor scenario. Two years on dialysis yielded a ratio of 1.26. Five years on dialysis indicated a ratio of 0.97 , and seven years yielded a ratio of 0.84 . Sensitivity analysis for years of life gained by bariatric surgery (one, three, five, seven, and ten years) yielded different benefit-to-cost ratios for the BS scenario ranging from 3.37 for one year gained to 3.75 for ten years gained. Different costs of dialysis per year $(\$ 90,000, \$ 100,000$, and $\$ 121,000)$ also resulted in a range of benefitto-cost ratios (Table 4). Benefit-to-cost ratios varied dramatically based on time of graft survival (10-, 13-, 15-, 18-, and 20-years) (Table 5). The initial analysis included zero post-operative costs for the donor who underwent BS. However, we also analyzed costs of $\$ 3,000 /$ year and $\$ 4,355 /$ year based on reports in the literature. The ratio was 3.34 when donor costs were $\$ 3,000 /$ year post-BS. When costs were $\$ 4,355 /$ year the benefit-cost ratio was 3.22. The highest approximate cost at which the BS scenario had a higher benefit-to-cost ratio than the OLKD scenario was $\$ 4,700 /$ year post-operatively (ratio $=3.20$ ).

Table 4. Benefit-to-Cost Ratios After Sensitivity Analysis for the Cost of Dialysis.

\begin{tabular}{|c|c|c|c|}
\hline & \multicolumn{3}{|c|}{ Cost of dialysis/year } \\
\hline Scenario & $\mathbf{\$ 9 0 , 0 0 0}$ & $\mathbf{\$ 1 0 0 , 0 0 0}$ & $\mathbf{\$ 1 2 1 , 0 0 0}$ \\
\hline Bariatric surgery & 3.9 & 3.78 & 3.64 \\
\hline Obese, live donor & 2.29 & 3.26 & 3.19 \\
\hline Deceased donor & 1.1 & 1.05 & 0.97 \\
\hline
\end{tabular}

Table 5. Benefit-to-Cost Ratios After Sensitivity Analysis for Years of Graft Survival.

\begin{tabular}{|c|c|c|c|c|c|}
\hline & \multicolumn{5}{|c|}{ Graft survival } \\
\hline Scenario & $\mathbf{1 0}$ years & $\mathbf{1 3}$ years & $\mathbf{1 5}$ years & $\mathbf{1 8}$ years & $\mathbf{2 0}$ years \\
\hline Bariatric surgery & 5.33 & 4.91 & 4.68 & 3.64 & 3.48 \\
\hline Obese, live donor & 3.43 & 3.3 & 3.19 & 3.01 & 2.9 \\
\hline Deceased donor & 1.08 & 0.97 & 0.96 & 0.96 & 0.95 \\
\hline
\end{tabular}

\section{Discussion}

There are numerous barriers to live donation. Morbid obesity is projected to have a significant impact on the number of suitable live donors available in the future [4-6]. Case reports of BS for a potential OLKD prior to donation have only been published two times to our knowledge but has likely been performed many more times $[49,50]$. Nguyen et al. recently presented their experience with live kidney donors who have undergone BS prior to donation at the American Society of Transplant Surgeons Winter Symposium [51]. In the past 5 years, 11 of their live donors had a history of BS. They reported no significant complications or impact on outcomes of the subsequent laparoscopic donor nephrectomy in patients who have had BS [51]. These reports indicate that BS for potential OLKDs could be an effective means of improving outcomes for both the recipient and donor following transplantation. However, these claims are controversial since little research has been done on the practice and bariatric surgical and live donation registries do not capture this information. In the interest of maximizing live donor safety, we sought to clarify the risks and benefits associated with this practice.

The results of our preliminary report indicate that there are potential benefits for the donor, recipient, and society if potential OLKDs underwent BS prior to donation. The cost-benefit analysis we performed hinges on the assumption that a potential OLKD who undergoes BS is then equivalent, economically, to a non-obese live donor. BS is not a panacea for all the medical comorbidities that make an OLKD a riskier donor than a non-obese live donor. However, for the sake of the cost-benefit analysis, this assumption had to be made. In reality, there would likely be a spectrum of results. Those potential donors who show the most improvement in comorbidities as a result of BS would reap the most economic and clinical benefit, while those potential donors who show little to no improvement would likely be unable to donate.

Recipients of live donor kidneys have superior patient and graft survival compared to recipients of deceased donor kidneys [2]. Although the recipient would need to remain on dialysis while the donor recovered from surgery and lost weight, the wait would be shorter in duration than that for a recipient of a deceased donor transplant. It is also possible that primary care physicians and nephrologists would alert the potential recipient to the fact that they will require transplantation or dialysis months to years before it is actually initiated. Thus, a potential donor could be instructed to undergo BS for weight loss in anticipation of future renal failure thereby obviating the one year wait on dialysis.

Additionally, BS provides the donor and society significant clinical and economic benefits. Sustained weight loss, reduced mortality, and improved hyperglycemia and hypertension are all advantages of BS [8-10, 20-22]. As with any procedure there are risks associated with BS. One important consideration is the increased frequency of hyperoxaluria that can occur following BS especially given that BS is being followed by nephrectomy in this scenario. Laparoscopic gastric sleeve procedures, however, are not associated with hyperoxaluria $[52,53]$. Given that this procedure is the most common type of BS in the United States, hyperoxaluria would not likely prove to be a substantial barrier to BS prior to live donation.

Following BS, society would no longer carry the extra costs incurred by a morbidly obese individual [13]. Furthermore, because the potential recipient would be on dialysis for less time, Medicare costs would be lower. For example, for every 50 recipients taken off the waitlist due to 
formerly obese live-donor kidneys now being available Medicare could save between $\$ 6.05$ million and $\$ 24.2$ million depending on how many years of dialysis were obviated for each individual. Most importantly, use of a live donor decreases the number of candidates on the waitlist for deceased donors and increases the likelihood that those individuals will receive a transplant.

The cost-benefit analysis highlights the economic benefits of potential OLKDs undergoing BS prior to donation. A benefit-to-cost ratio of 3.64 from our calculations indicates moderate effectiveness, especially given that many of the cost assumptions we utilized were relatively high. The difference in benefit-to-cost ratio was not substantially greater for the BS scenario compared to donation with an obese live donor (3.64 vs. 3.19, respectively). However, the benefit-tocost ratio for the BS before living donation varies based on the number of years of life that are gained from BS. Even with only one year of life gained from BS, this scenario is still more beneficial compared to the use of an OLKD (3.37 vs. 3.19), and with 10 years of life gained from $\mathrm{BS}$ it is even more effective (3.75 vs. 3.19). Furthermore, we found that BS prior to living donation is still superior than the use of an OLKD even after assuming equal graft survival. Our results indicate that with $10-, 13-, 15-, 18-$, and 20-years of graft survival, the BS scenario is associated with a higher benefit-to-cost ratio than the use of an OLKD with equal graft survival. The assumption of equal graft survival was made as a conservative estimate. As outlined, a recipient of an allograft from a living donor will likely have superior graft survival compared to a recipient of an allograft from an OLKD or a deceased donor. Thus, the assumption of equal graft survival highlights the superior outcomes for the BS scenario and suggests the outcomes could be better still, if less conservative assumptions are made regarding graft survival. It is also possible that the disability weight for an obese individual would be lower which would result in a greater difference between the two. Additionally, according to our analysis the BS scenario is only associated with a higher benefit-to-cost ratio than the OLKD scenario up to a certain point. As the healthcare costs for a donor undergoing $\mathrm{BS}$ rise above $\$ 4,700$, the ratio becomes inferior to that of the OLKD. It should be noted, however, that this is partially due to the fact that, in our model, the donor who undergoes BS has a longer life expectancy and thus accumulates more costs. Additionally, it was assumed that these costs would be constant year by year when in reality they likely vary. Some reports show that costs remain high in the first year after BS and then decrease significantly by the third year [18]. while others suggest the cost is relatively constant each year [17]. We could have discounted the cost each year to mimic the reported decreases, however, there was no consistent evidence on the appropriate rate, nor do many studies have follow-up periods as long as our model. Thus, in order to again maintain conservative estimates, we chose to keep the cost constant.

Despite these benefits, there are risks that are unaccounted for by the nature of this analysis. Given that the cost-benefit analysis represents a view of an average kidney transplant recipient and an average obese donor who undergoes BS there is potential for a wide spectrum of results. For example, $15 \%$ of individuals who undergo BS will not have sufficient weight loss, $9 \%$ will have unresolved diabetes, and $15 \%$ will have hypertension and dyslipidemia remission postBS therefore increasing the risk associated with them undergoing live-donor nephrectomy [23,54]. In addition, it is possible that some potential OLKDs will undergo BS and subsequently choose to forego live donation.

Increasing the utilization of OLKDs has become more common as physicians strategize innovative ways to expand the donor pool in the
United States. Our report suggests that an OLKD would probably be a better option than a deceased donor as far as patient and graft survival are concerned [2]. However, donation from an OLKD is associated with substantial peri- and post-operative risks for both the recipient and donor [43-45]. Furthermore, an obese individual is at a much higher risk of developing ESRD, and, therefore, potentially requiring kidney transplantation in the future.

Donation from an OLKD could benefit the recipient and society. The recipient does not need to spend as much time on dialysis and the waitlist, thereby limiting the potential for morbidity and mortality and saving money. However, given that an OLKD would still likely be obese following donation and also be at an increased risk of ESRD there are significant, possible, future costs. The risks associated with donation from an OLKD are likely greater than those incurred due to BS. However, without improved tracking of each of these scenarios, it is impossible to know for sure whether BS prior to donation is associated with superior outcomes.

Deceased donor transplantation is associated with superior outcomes compared to dialysis $[12,46,47]$. However, patient and graft outcomes are inferior when compared to live donation. ${ }^{16}$ Additionally, time spent on the waitlist is associated with an increased mortality rate, inferior quality of life, and substantial costs $[2,12,47]$. Our analysis suggests that a live donor, even one that is obese, is preferable to a deceased donor.

The cost-benefit analysis indicated that transplantation from a live donor who has undergone BS is associated with a benefit-to-cost ratio about three times greater than transplantation with a deceased donor (benefit-to-cost ratios of 3.64 vs. 0.97 , respectively). Thus, our results suggest that an OLKD who has undergone BS, and an OLKD are both preferable, financially, to deceased donor transplantation.

Our analysis has a number of strengths. First, it represents an overview of the relevant kidney transplantation and BS research. Additionally, it provides an objective cost-benefit analysis to quantify our findings. Finally, it explores an issue that has the potential to increase the number of live kidney donors and decrease waitlist times. One weakness is the limited number of cases reporting outcomes for OLKDs who have undergone BS. Without these reports, it is difficult to draw strong conclusions about our results. Additionally, without these reports it is impossible to know definitively whether or not offering BS to potential OLKD prior to donation would compromise donor welfare. Furthermore, there are inherent limitations to a cost-benefit analysis. A number of assumptions must be made in order to attempt to provide objective data on the potential of having OLKDs undergo BS prior to donation. These assumptions are based on published literature and are strengthened by the number of sensitivity analyses performed. Despite the fact that such assumptions are an unavoidable weakness, we believe this report provides a promising, preliminary framework for a provocative idea. In that light, it should be made clear that the data we have presented here offer encouraging insight, but no definitive conclusions can be made at this time given the lack of long term outcomes.

\section{Conclusion}

BS for potential OLKDs is a controversial strategy for increasing the number of live kidney donors. We believe that it is being done with increasing frequency. There are no databases to capture patients who have undergone both procedures. Therefore, at this time, we can only calculate what we believe are potential risks and benefits. The main objective of this report was to evaluate those risks and benefits in order 
to maximize patient safety. Our results seem to indicate that the benefits of such a strategy outweigh the risks. Furthermore, we demonstrated that it could be a cost-efficient approach compared to donation from an OLKD or a deceased donor. In light of these results, we recommend further investigations to evaluate outcomes in OLKD who undergo BS prior to donation compared to a control population. Additionally, a registry of such patients and their outcomes would help us further evaluate the clinical and economic feasibility of such a practice.

\section{Disclosures}

Mr. Brooks, Mr. Mitro, Mr. DeLeonibus, Dr. McGreevey, Ms. Cash, and Dr. Ortiz have no conflicts of interest or financial ties to disclose.

\section{Author contributions} analysis

Brooks J: wrote the manuscript and performed the cost-benefit

Mitro G: wrote the manuscript and reviewed the cost-benefit analysis

\section{DeLeonibus A: wrote and reviewed the manuscript}

McGreevey W: reviewed and edited the manuscript and costbenefit analysis

Cash A: wrote and reviewed the manuscript

Jain S: reviewed the manuscript

Ortiz J: study idea and design, reviewed and edited the manuscript and cost-benefit analysis

\section{References}

1. Organ donation and transplantation statistics. National Kidney Foundation. https:/ www.kidney.org/news/newsroom/factsheets/Organ-Donation-and-TransplantationStats

2. OPTN/SRTR Annual Data Report (2012) Organ Procurement and Transplantation Network. http://srtr.transplant.hrsa.gov/annual_reports/2012/pdf/01_kidney_13.pdf

3. Ahmadi A, Lafranca J, Claessens L, Imamdi MSR, Ijzermans JNM, et al. (2015) Shifting paradigms in eligibility criteria for live kidney donation: a systematic review. Kidney International 87: 31-45

4. Mandelbrot DA, Pavlakis M, Danovitch GM, Johnson SR, Karp SJ, et al. (2007) The medical evaluation of living kidney donors: a survey of US transplant centers. Am J Transplant 7: 2333-2343. [Crossref]

5. Sachdeva M, Sunday S, Israel E, Varghese J, Rosen L, et al. (2013) Obesity as a barrier to living kidney donation: a center-based analysis. Clin Transplant 27: 882-887. [Crossref]

6. Flegal KM, Carroll MD, Kit BK, Ogden CL (2012) Prevalence of obesity and trends in the distribution of body mass index among US adults, 1999-2010. JAMA 307: 491497. [Crossref]

7. Whitlock G, Lweington S, Sherliker P et al. (2009) BMI and cause-specific mortality in 900000 adults: collaborative analyses of 57 prospective studies. Lancet 373: 10831096. [Crossref]

8. Sjöström L, Peltonen M, Jacobson P, Ahlin S, Andersson-Assarsson J, et al. (2014) Association of bariatric surgery with long-term remission of type 2 diabetes and with microvascular and macrovascular complications. JAMA 311: 2297-2304. [Crossref]

9. Schauer PR, Bhatt DL, Kirwan JP, Wolski K, Brethauer SA, et al. (2014) Bariatric surgery versus intensive medical therapy for diabetes--3-year outcomes. $N$ Engl J Med 370: 2002-2013. [Crossref]

10. Maggard-Gibbons M, Maglione M, Livhits M, Ewing B, Maher AR, et al. (2013) Bariatric surgery for weight loss and glycemic control in non-morbidly obese adults with diabetes: a systematic review. JAMA 309: 2250-2261

11. Chang AR, Chen Y, Still C, Wood GC, Kirchner HL, et al. (2016) Bariatric surgery is associated with improvement in kidney outcomes. Kidney Int 90: 164-171. [Crossref]
12. Held PJ, McCormick F, Ojo A, Roberts JP (2016) A Cost-Benefit Analysis of Government Compensation of Kidney Donors. Am J Transplant 16: 877-885. [Crossref]

13. Maciejewski ML, Arterburn DE (2013) Cost-effectiveness of bariatric surgery. JAMA 310: 742-743. [Crossref]

14. Cawley J, Meyerhoefer C, Biener A, Hammer M, Wintfeld N (2015) Savings in medical expenditures associated with reductions in body mass index among US adults with obesity, by diabetes status. Pharmacoeconomics 33: 707-722. [Crossref]

15. Cutler D (2005) Your Money or Your Life. Oxford University Press.

16. Peeters A, Barendregt JJ, Willekens F, Mackenbach JP, Al Mamun A, et al. (2003) Obesity in adulthood and its consequences for life expectancy: a life-table analysis. Ann Intern Med 138: 24-32. [Crossref]

17. Hoerger T, Kahn H, Zhang P, Barker L, Segel J, et al. (2010) Cost-effectiveness of bariatric surgery for severely obese adults with diabetes. Diabetes Care 33:1933-1939. [Crossref]

18. Makary M, Clark J, Shore A, Magnuson TH, Richards T, et al. (2010) Medication Utilization and Annual Health Care Costs in Paitents with Type 2 Diabetes Mellitus Before and After Bariatric Surgery. Surg 145: 726-731. [Crossref]

19. Purnell T, Auguste P, Crews D, Lamprea-Montealegre J, Olufade T, et al. (2013) Comparison of life participation activities among adults treated with hemodialysis, peritoneal dialysis, and kidney transplantation: A systematic review. Am J Kidney Dis 62: 953-973. [Crossref]

20. Sjöström L, Narbro K, Sjöström CD, Karason K, Larsson B, et al. (2007) Effects of bariatric surgery on mortality in Swedish obese subjects. N Engl J Med 357: 741-752. [Crossref]

21. Silvestre V, Ruano M, Domínguez Y, Castro R, García-Lescun MC, et al. (2004) Morbid obesity and gastric bypass surgery: biochemical profile. Obes Surg 14: 1227 1232. [Crossref]

22. Douglas IJ, Bhaskaran K, Batterham RL, Smeeth L (2015) Bariatric Surgery in the United Kingdom: A Cohort Study of Weight Loss and Clinical Outcomes in Routine Clinical Care. PLoS Med 12: e1001925. [Crossref]

23. Sundstrom J, Bruze G, Ottosson J (2016) Weight loss and heart failure. Presented at the 2016 AHA Scientific Sessions.

24. Schauer PR, Bhatt DL, Kirwan JP, Wolski K, Brethauer SA, et al. (2014) Bariatric surgery versus intensive medical therapy for diabetes--3-year outcomes. $N$ Engl J Med 370: 2002-2013. [Crossref]

25. Synder B, Nguyen A, Scarbourough T, Yu S, Wilson E (2009) Comparison of those who succeed in losing significant excessive weight after bariatric surgery and those who fail. Surg Endosc 23: 2302-2306. [Crossref]

26. Hutter M, Schirmer B, Jones D, Ko CY, Cohen ME, et al. (2012) First report from the American College of Surgeons - bariatric surgery center network: laparoscopic sleeve gastrectomy has morbidity and effectiveness positioned between the band and the bypass. Ann Surg 254: 410-422. [Crossref]

27. Kortram K, Ijzermans J, Dor F (2016) Perioperative Events and Complications in Minimally Invasive Live Donor Nephrectomy: A systematic Review and MetaAnalysis. Transplantation 100: 2264-2275. [Crossref]

28. Livingston EH (2005) Hospital costs associated with bariatric procedures in the United States. Am J Surg 190: 816-820. [Crossref]

29. Biancone L, Cozzi E, López-Fraga M, Nanni-Costa A (2016) Long-term outcome of living kidney donation: Position paper of the European Committee on Organ Transplantation (CD-P-TO), Council of Europe. Transpl Int 29: 129-131. [Crossref]

30. Khan S, Rock K, Baskara A, Qu W, Nazzal M, et al. (2016) Trends in bariatric surgery from 2008 to 2012. Am J Surg 211: 1041-1046. [Crossref]

31. Abramowicz D, Cochat P, Claas FH, Heemann U, Pascual J, et al. (2015) European Renal Best Practice Guideline on kidney donor and recipient evaluation and perioperative care. Nephrol Dial Transplant 30: 1790-1797. [Crossref]

32. Cohney S, Kanellis J, Howell M; CARI (2010) The CARI guidelines. Donor renal function. Nephrology (Carlton) 15: S137-S145. [Crossref]

33. Joint Working Party of the British Transplantation Society and the Renal Association (2011) United Kingdom Guidelines for Living Donor Kidney Transplantation.

34. Massie AB, Leanza J, Fahmy LM, Chow EK, et al. (2016) A Risk Index for Living Donor Kidney Transplantation. Am J Transplant 16: 2077-2084. [Crossref] 
35. Reese PP, Feldman HI, Asch DA, Thomasson A, Shults J, et al. (2009) Short-term outcomes for obese live kidney donors and their recipients. Transplantation 88: 662671. [Crossref]

36. Locke JE, Sawinski D, Reed RD, Shelton B, MacLennan PA, et al. (2017) Apolipoprotein L1 and Chronic Kidney Disease Risk in Young Potential Living Kidney Donors. Ann Surg. [Crossref]

37. Muzaale A, Massie A, Anjum S, Liao C, Garg AX, et al. (2016) Recipient Outcomes Following Transplantation of Allografts From Live Kidney Donors Who Subsequently Developed End-Stage Renal Disease. Am J Transplant 16: 3532-3539. [Crossref]

38. Hsu CY, McCulloch CE, Iribarren C, Darbinian J, Go AS (2006) Body mass index and risk for end-stage renal disease. Ann Intern Med 144: 21-28. [Crossref]

39. Wadden TA, Sarwer DB, Fabricatore AN, et al. (2007) Psychosocial and behavioural status of patients undergoing bariatric surgery: what to expect before and after surgery Med Clin North Am 91: 451-469. [Crossref]

40. Narbro K, Jonsson E, Larsson B, et al. (1996) Economic consequences of sick-leave and early retirement in obese Swedish women. Int J Obes 20: 895-903. [Crossref]

41. Frezza EE, Wachtel MS, Ewing BT (2006) The impact of morbid obesity on the state economy: an initial evaluation. Surg Obes Relat Dis 2: 504-508. [Crossref]

42. Wolf AM, Colditz GA (1994) The cost of obesity: the US perspective. Pharmacoeconomics 5: 34-37. [Crossref]

43. Jacobs SC, Cho E, Dunkin BJ, Bartlett ST, Flowers JL, et al. (2000) Laparoscopic nephrectomy in the markedly obese living renal donor. Urology 56: 926-929. [Crossref]

44. Heimbach J, Taler S, Prieto M, Cosio FG, Textor SC, et al. (2005) Obesity in living kidney donors: clinical characteristics and outcomes in the era of laparoscopic donor nephrectomy. Am J Transplant 5: 1057-1064. [Crossref]
45. Lentine K, Lam N, Axelrod M, Schnitzler MA, Garg AX, et al. (2016) Perioperative complications after living kidney donation: A national study. Am J Transplant 16: 18481857. [Crossref]

46. Wolfe R, Ashby V, Milford E, Ojo AO, Ettenger RE, et al. (1999) Comparison of mortality in all patients on dialysis, patients on dialysis awaiting transplantation, and recipients of a first cadaveric transplant. $N$ Engl J Med 341: 1725. [Crossref]

47. Stokes J (2011) Consequences of frequent hemodialysis: comparison to conventional hemodialysis and transplantation. Trans Am Clin Climatol Assoc 122: 124-136. [Crossref]

48. Annual Data Report (2015) United States Renal Data System. https://www.usrds.org adr.aspx

49. Branco A, Branco F, Kondo W (2007) Laparoscopic live donor nephrectomy in patients surgically treated for morbid obesity. Int Braz J Urol 33: 377-379. [Crossref]

50. Koshy A, Wilkinson S, Coombes J, Fassett R (2010) Laparoscopic adjustable gastric band in an obese unrelated living donor prior to kidney transplantation: a case report. $J$ Med Case Rep 4: 107. [Crossref]

51. Nguyen MT, Carpenter D, Mathur A, Van Bever J, et al. (2017) Bariatric surgery prior to living kidney donation: A solution to expand the donor pool. (abstract) ASTS Winter Symposium.

52. Craig BM, Tseng DS (2002) Cost-effectiveness of gastric bypass for severe obesity. Am J Med 113: 491-498. [Crossref]

53. Semins MJ, Asplin JR, Steele K, Assimos DG, Lingeman JE, et al. (2010) The effect of restrictive bariatric surgery on urinary stone risk factors. Urology 76: 826-829. [Crossref]

54. Chang SH, Stoll CR, Song J, Varela JE, Eagon CJ, et al. (2014) The effectiveness and risks of bariatric surgery: an updated systematic review and meta-analysis, 2003-2012. JAMA Surg 149: 275-287. [Crossref]

Copyright: (C2017 Brooks J. This is an open-access article distributed under the terms of the Creative Commons Attribution License, which permits unrestricted use, distribution, and reproduction in any medium, provided the original author and source are credited. 